\title{
Vibration Analysis of Non-uniform Beams Resting on Two Layer Elastic Foundations Under Axial and Transverse Load Using (GDQM)
}

\author{
Ramzy M. Abumandour ${ }^{1, ~ *}$, Islam M. Eldesoky ${ }^{1}$, Mohamed A. $\operatorname{Safan}^{2}$, R. M. Rizk-Allah ${ }^{1}$, \\ Fathi A. Abdelmgeed ${ }^{3}$ \\ ${ }^{1}$ Basic Engineering Sciences Department, Faculty of Engineering, Menofia University, Menofia, Egypt \\ ${ }^{2}$ Department of Civil Engineering, Faculty of Engineering, Menofia University, Menofia, Egypt \\ ${ }^{3}$ Department of Physics and Engineering Mathematics, Faculty of Engineering, Kafr El-Sheikh University, Kafr El-Sheikh, Egypt
}

Email address:

ramzy_0000@yahoo.com (R. M. Abumandour)

*Corresponding author

\section{To cite this article:}

Ramzy M. Abumandour, Islam M. Eldesoky, Mohamed A. Safan, R. M. Rizk-Allah, Fathi A. Abdelmgeed. Vibration Analysis of Nonuniform Beams Resting on Two Layer Elastic Foundations Under Axial and Transverse Load Using (GDQM). International Journal of Mechanical Engineering and Applications. Vol. 5, No. 2, 2017, pp. 70-77. doi: 10.11648/j.jimea.20170502.11

Received: January 1, 2017; Accepted: January 19, 2017; Published: March 4, 2017

\begin{abstract}
The natural frequencies of non-uniform beams resting on two layer elastic foundations are numerically obtained using the Generalized Differential Quadrature (GDQ) method. The Differential Quadrature (DQ) method is a numerical approach effective for solving partial differential equations. A new combination of GDQM and Newton's method is introduced to obtain the approximate solution of the governing differential equation. The GDQ procedure was used to convert the partial differential equations of non-uniform beam vibration problems into a discrete eigenvalues problem. We consider a homogeneous isotropic beam with various end conditions. The beam density, the beam inertia, the beam length, the linear $\left(\mathrm{k}_{1}\right)$ and nonlinear $\left(\mathrm{k}_{2}\right)$ Winkler (normal) parameters and the linear $\left(\mathrm{k}_{3}\right)$ Pasternak (shear) foundation parameter are considered as parameters. The results for various types of boundary conditions were compared with the results obtained by exact solution in case of uniform beam supported on elastic support.
\end{abstract}

Keywords: Non-linear Elastic Foundation, Vibration Analysis, Non-uniform Beam, Mode Shapes and Natural Frequencies, GDQM and Newton's Method

\section{Introduction}

Beams resting on linear and non-linear elastic foundations have many practical engineering applications as railroad tracks, highway pavement, buried pipelines and foundation beams. Due to the difficulty of mathematical nature of the problem, a few analytical solutions limited to special cases for vibrations of non-uniform beams resting on non-linear elastic foundations are found. Many methods are used to obtain the vibration behavior of different types of linear or nonlinear beams resting on linear or nonlinear foundations such as finite element method [1-3], transfer matrix method [4], Rayleigh-Ritz method [5], differential quadrature element method (DQEM) [6-10], Galerkin procedure [11, 12] and [13-15]. There are various types of foundation models such as Winkler, Pasternak, Vlasov, etc. that have been used in the analysis of structures on linear and non-linear elastic foundations. Also, There are different beam types such as the Euler-Bernoulli which for slender beams and Timoshenko beam model for moderately short and thick beams. Balkaya et al. [16] studied vibration of a uniform Euler beam on elastic foundation using Differential Transform Method. Also, Ozturk and Coskun [17] studied the same problem using HPM. Avramidis and Morfidis [18] analyzed bending of beams on three-parameter elastic foundation.

Abrate et al. [19, 21] studied the vibrations of non-uniform rods and beams using the Rayleigh-Ritz scheme. Hodges et al. [22] used a discrete transfer matrix scheme to compute the fundamental frequencies and the corresponding modal 
shapes. Sharma and DasGupta [23] used the Green's functions to study the bending of axially constrained beams resting on nonlinear Winkler type elastic foundations. Beaufait and Hoadley [24] used the midpoint difference technique to solve the problem of elastic beams resting on a linear foundation. Kuo and Lee [25] used the perturbation method to investigate the deflection of non-uniform beams resting on a nonlinear elastic foundation. Chen [26] used the differential quadrature element approach to obtain the numerical solutions for beams resting on elastic foundations.

Bagheri et al. [27] studied the nonlinear responses of clamped-clamped buckled beam. They used two efficient mathematical techniques called variational approach and Laplace iteration method in order to obtain the responses of the beam vibrations. Nikkar et al. [28] studied the nonlinear vibration of Euler-Bernoulli using analytical approximate techniques. Li and Zhang [29] used the B-spline function to derive a dynamic model of a tapered beam. Ramzy et al. [30] presented a new technique of GDQM for determining the deflection of a non-uniform beam resting on a non-linear elastic foundation, subjected to axial and transverse distributed force. Ramzy et al. [31] presented some problems in structural analysis resting on fluid layer using GDQM. Ramzy et al. [32] studied free vibration of uniform and non-uniform beams resting on fluid layer under axial force using the GDQM. The details of the DQM and its applications can be found in [33-34].

From previous studies, there are no any attempts to study vibration of non-uniform beam resting on two non-linear elastic foundations with the linear and nonlinear Winkler (normal) parameters and the linear Pasternak (shear) foundation parameter. The main goal of this study, to present a new combination of a GDQM and Newton's method to obtain the fundamental frequencies and the corresponding modal shapes of non-uniform beams resting on two layer elastic foundations under appropriate boundary conditions.

\section{Formation}

The kinetic energy of a beam with a non-uniform crosssection resting on an elastic foundation is as follows:

$$
T=\frac{\rho A}{2} \int_{0}^{L}\left[\frac{\partial v(x, t)}{\partial t}\right]^{2} d x, 0 \leq \mathrm{x} \leq \mathrm{L} .
$$

Where the length of the non-uniform beam L, the vertical displacement $v$, the cross- sectional area of the beam A and the density of the beam material $\rho$.

The strain energy of a non-uniform beam resting on an elastic foundation can be derived as follows:

$$
\begin{array}{r}
U=\frac{1}{2} \int_{0}^{L} E I\left[\frac{\partial^{2} v(x, t)}{\partial x^{2}}\right]^{2} d x+\frac{1}{2} k \int_{0}^{L}[v(x, t)] d x \\
\frac{\partial^{2}}{\partial x^{2}}\left(E I \frac{\partial^{2} v}{\partial x^{2}}\right)+\rho A \frac{\partial^{2} v}{\partial t^{2}}+p \frac{\partial^{2} v}{\partial x^{2}}+k_{1} v+k_{2} v^{3}-k_{3} \frac{\partial^{2} v}{\partial x^{2}}=f(x, t), 0 \leq x \leq L
\end{array}
$$

Where the inertia of the beam I, the constant of the foundation $\mathrm{k}$ and Young's modulus of the beam material $\mathrm{E}$.

Due to the axial loading, the work done can be written as follows,

$$
\text { Work }=\frac{1}{2} \int_{0}^{L} p\left[\frac{\partial v(x, t)}{\partial x}\right]^{2} d x
$$

Where, $\mathrm{p}$ is the axial force.

The Hamilton's principle is given by:

$$
\int_{t_{1}}^{t_{2}}(\delta T-\delta U+\delta W) \cdot d t=0
$$

where $\delta \mathrm{W}$ is the virtual work.

Substituting from Equations (1), (2) and (3) into Equation (4) yields,

$$
\frac{\partial^{2}}{\partial x^{2}}\left(E I \frac{\partial^{2} v}{\partial x^{2}}\right)+\rho A \frac{\partial^{2} v}{\partial t^{2}}+p \frac{\partial^{2} v}{\partial x^{2}}+k v=0
$$

Equation (5) represents the equation of motion of nonuniform beam resting on elastic foundations under axial force.

The corresponding boundary conditions are as follows:

For Clamped-Clamped supported (C-C);

$$
\begin{aligned}
& W(0)=\frac{d W(0)}{d X}=0 \\
& W(L)=\frac{d W(L)}{d X}=0
\end{aligned}
$$

For Simply-Simply supported (S-S);

$$
\begin{aligned}
& W(0)=\frac{d^{2} W(0)}{d X^{2}}=0 \\
& W(L)=\frac{d W^{2}(L)}{d X^{2}}=0
\end{aligned}
$$

For Clamped-Simply supported (C-S);

$$
\begin{aligned}
& W(0)=\frac{d W(0)}{d X}=0 \\
& W(L)=\frac{d W^{2}(L)}{d X^{2}}=0
\end{aligned}
$$

The vibration equation of a flexural non-uniform beam resting on two-layer elastic foundation is given as: 
To obtain the natural frequencies and mode shapes, one can assume:

$$
\begin{aligned}
& v(\mathrm{x}, \mathrm{t})=\mathrm{V}(\mathrm{x}) \mathrm{e}^{i \omega t}, \\
& f(\mathrm{x}, \mathrm{t})=q(\mathrm{x}) \mathrm{e}^{i \omega t} .
\end{aligned}
$$

Where the amplitude of free vibration $\mathrm{V}(\mathrm{x})$, the natural frequency of the beam $\omega$ and the external dynamic distributed load applied $q(x, t)$.

Substituting form Equations (13) and (14) into Equation (12) yields

$$
\begin{gathered}
\frac{\partial^{2}}{\partial x^{2}}\left(E I \frac{d^{2} V}{d x^{2}}\right) \exp (i \omega t)+\rho A V \omega^{2} \exp (i \omega t)+p \frac{\partial^{2} V}{\partial x^{2}} \exp (i \omega t)+k_{1}(V \exp (i \omega t))+ \\
k_{2}\left(V^{3} \exp (3 i \omega t)\right)-k_{3} \frac{d^{2} V}{d x^{2}} \exp (i \omega t)=\mathrm{q}(\mathrm{x}) \exp (i \omega t), \quad 0<x<L \\
\frac{\partial^{2}}{\partial x^{2}}\left(E I \frac{d^{2} V}{d x^{2}}\right)+p \frac{\partial^{2} V}{\partial x^{2}}+k_{1} V+k_{2} V^{3}-k_{3} \frac{d^{2} V}{d x^{2}}-\mathrm{q}(\mathrm{x})=\rho A V \omega^{2}, \quad 0<x<L
\end{gathered}
$$

Through the normalization process we can transform Equation (16) into non-dimensional form as follows,

$$
S(X) \cdot \frac{d^{4} W}{d X^{4}}+2 \frac{d S(X)}{d X} \cdot \frac{d^{3} W}{d X^{3}}+\frac{d S^{2}(X)}{d X^{2}} \cdot \frac{d^{2} W}{d X^{2}}+P \frac{d^{2} W(X)}{d X^{2}}+K_{1} \cdot W+K_{2} \cdot W^{3}-K_{3} \frac{d^{2} W(X)}{d X^{2}}-F=\Omega^{2} \cdot W
$$

The non-dimensional coefficients are:

$$
\begin{gathered}
W=\frac{V}{L}, \quad X=\frac{x}{L}, \quad P=\frac{p L^{2}}{E I_{0}}, \quad K_{1}=\frac{k_{1} L^{4}}{E I_{0}}, \quad K_{2}=\frac{k_{2} L^{6}}{E I_{0}}, \\
K_{3}=\frac{k_{3} L^{2}}{E I_{0}}, \quad \Omega^{2}=\frac{\rho A L^{4} \omega}{E I_{0}}, \quad S(X)=\frac{E I}{E I_{0}}, \quad \text { and } \mathrm{F}(\mathrm{X})=\frac{q(x) L^{3}}{E I_{0}} .
\end{gathered}
$$

Where the non-dimensional deflection of the beam $\mathrm{W}$, the non-dimensional axial loading $\mathrm{P}$, the non-dimensional foundation linear stiffness $\mathrm{K}$, the non-dimensional frequency of the beam $\Omega$, the beam's flexural rigidity EI, the mass per unit length $\rho \mathrm{A}$ and the inertia ratio $\mathrm{S}(\mathrm{X})$.

Equation (17) is a $4^{\text {th }}$ order ordinary differential equation with inertia ratio $S(X)=\left(1+\alpha_{1} X\right)^{\alpha_{2}}$. In this section, we will study two cases of inertia ratio $\mathrm{S}(\mathrm{X})$; the first case $\alpha_{1}=0.5$, $\alpha_{2}=1$ and the second case $\alpha_{1}=-1, \alpha_{2}=1$.

\section{Solution of the Problem}

The method of GDQ is employed to solve the problem. This method requires to descretize the domain of the problem into $N$ pointes. Then the derivatives at any points are approximated by a weighted linear summation of all the functional values along the descretized domain, as follows [33-34]:

$$
f_{x}\left(x_{i}\right)=\left.\frac{d f}{d x}\right|_{x_{i}}=\sum_{j=1}^{N} A_{i j} \cdot f\left(x_{j}\right), \text { for } \mathrm{i}=1,2,3, \ldots, \mathrm{N} .
$$

Where, $A_{i j}$ represented the weighting coefficient, and $N$ is the number of grid points in the whole domain. Equation (18) is called Differential Quadrature (DQ) technique. It should be noted that the weighting coefficients $A_{i j}$ are different at different location of $x_{i}$. The key to DQ is to determine the weighting coefficients for the discretization of a derivative of any order.

The weighting coefficient can be determined by making use of Lagrange interpolation formula as follows:

$$
\begin{gathered}
g_{k}(x)=\frac{M(x)}{\left(\mathrm{x}-\mathrm{x}_{\mathrm{k}}\right) \mathrm{M}^{(1)}\left(\mathrm{x}_{\mathrm{k}}\right)}, \text { where } \mathrm{k}=1,2,3, \ldots, \mathrm{N} \\
M(x)=\left(x-x_{1}\right)\left(x-x_{2}\right) \ldots \ldots .\left(x-x_{N}\right) \\
M^{(1)}\left(x_{i}\right)=\prod_{k=1, k \neq i}^{N}\left(x_{i}-x_{N}\right)
\end{gathered}
$$

By applying Equation (19) at $\mathrm{N}$ grid points, they obtained the following algebraic formulations to compute the weighting coefficients $A_{i j}$. 


$$
\begin{gathered}
A_{i j}=\frac{1}{x_{i}-x_{j}} \prod_{k=1, k \neq i, j}^{N} \frac{\left(x_{i}-x_{k}\right)}{\left(x_{j}-x_{k}\right)}, \quad j \neq i \\
A_{i i}=\sum_{k=1, k \neq i}^{N} \frac{1}{x_{i}-x_{k}}
\end{gathered}
$$

For calculating the weighting coefficients of $\mathrm{m}^{\text {th }}$ order

$$
\left[A^{(m)}\right]=\left[A^{(1)}\right] \cdot\left[A^{(m-1)}\right]=\left[A^{(m-1)}\right] \cdot\left[A^{(1)}\right] \mathrm{m}=2,3,4, \ldots, \mathrm{N}-1
$$

The accuracy of the results obtained by DQM, is affected by choosing of the number of grid points, $N$, and the type of sampling points, $x_{i}$. It is found that the optimal selection of the sampling grid points in the vibration problems, are chosen according to Gauss-Chebyshev-lobatto points [3334],

$$
X(i)=\frac{1}{2}\left[1-\cos \left(\frac{i-1}{N-1} \pi\right)\right], \mathrm{i}=1,2,3, \ldots, N
$$

Applying the GDQ discretization scheme to the nondimensional governing Equation (17) yields;

$$
S(X)\left(\sum_{j=1}^{N} D_{i j} \cdot W_{j}\right)+2 S^{(1)}\left(X_{i}\right)\left(\sum_{j=1}^{N} C_{i j} \cdot W_{j}\right)+S^{(2)}\left(X_{i}\right)\left(\sum_{j=1}^{N} B_{i j} \cdot W_{j}\right)+P\left(\sum_{j=1}^{N} B_{i j} \cdot W_{j}\right)+K_{1} W_{i}+
$$

$$
K_{2} W_{i}^{3}-K_{3}\left(\sum_{j=1}^{N} B_{i j} W_{j}\right)-F=\Omega^{2} W_{i}, \mathrm{i}=1,2,3, \ldots, \mathrm{N} .
$$

Where $W_{i}$ is the functional value at the grid points $X_{i}$. $B_{i j}, C_{i j}$ and $D_{i j}$ is the weighting coefficient matrix of the second, third and forth order derivatives.

Applying the GDQ discretization scheme to the boundary conditions are given by Equation (6) through (11) we obtain,

For Clamped-Clamped $(\mathrm{C}-\mathrm{C})$ yields;

$$
\begin{array}{r}
W_{1}=\sum_{j=1}^{N} A_{1 j} W_{j}=0 \\
W_{N}=\sum_{j=1}^{N} A_{N j} W_{j}=0
\end{array}
$$

For Simply-Simply (S-S) yields;

$$
\begin{gathered}
W_{1}=\sum_{j=1}^{N} B_{1 j} W_{j}=0 \\
W_{N}=\sum_{j=1}^{N} B_{N j} W_{j}=0
\end{gathered}
$$

For Clamped-Simply (C-S) yields;

$$
\begin{gathered}
W_{1}=\sum_{j=1}^{N} A_{1 j} W_{j}=0 \\
W_{N}=\sum_{j=1}^{N} B_{N j} W_{j}=0
\end{gathered}
$$

Using the method of direct Substitutions of the Boundary Conditions into the Governing Equations (SBCGE). The essence of the approach is that the Dirichlet condition is implemented at the boundary points, while the derivative condition is discretized by the DQM. The discretized derivatives conditions at two ends are then combined to give the solutions $W_{2}$ and $W_{N-1}$. The expression for $W_{2}$ and $W_{N-1}$ are then substituted into the discrete governing equation which is applied to the interior points $3 \leq i \geq N-2$. The dimension of the equation system using this approach is $(N-4) \times(N-4)$.

For clamped and simply supported end conditions, the discrete boundary conditions using the DQM can be written as:

$$
\begin{gathered}
W_{1}=0 \\
\sum_{k=1}^{N} C_{1, k}^{\left(n_{0}\right)} \cdot W_{k}=0 \\
W_{N}=0 \\
\sum_{k=1}^{N} C_{N, k}^{\left(n_{1}\right)} \cdot W_{k}=0 .
\end{gathered}
$$

Where $n_{0}$ and $n_{1}$ may be taken as either 1 or 2. By choosing the value of $n_{0}$ and $n_{1}$, Equation (33) through (36) can give the following four sets of boundary conditions,

$\mathrm{n}_{0}=1, \mathrm{n}_{1}=1$ - clamped-clamped supported.

$\mathrm{n}_{0}=1, \mathrm{n}_{1}=2$ - clamped-simply supported.

$\mathrm{n}_{0}=2, \mathrm{n}_{1}=1$ - simply-clamped supported.

$\mathrm{n}_{0}=2, \mathrm{n}_{1}=2$ - simply supported-simply supported.

Equations (33) and (35) can be easily substituted into the governing equation. We can couple Equation (34) and (36) together to give two solutions, $W_{2}$ and $W_{N-1}$, as

$$
W_{2}=\frac{1}{A X N} \cdot \sum_{k=3}^{N-2} A X K 1 \cdot W_{k},
$$




$$
W_{N-1}=\frac{1}{A X N} \cdot \sum_{k=3}^{N-2} A X K N \cdot W_{k}
$$

Where;

$$
\begin{gathered}
A X K 1=C_{1, k}^{\left(n_{0}\right)} \cdot C_{N, N-1}^{\left(n_{1}\right)}-C_{1, N-1}^{\left(n_{0}\right)} \cdot C_{N, k}^{\left(n_{1}\right)} \\
A X K N=C_{1,2}^{\left(n_{0}\right)} \cdot C_{N, k}^{\left(n_{1}\right)}-C_{1, k}^{\left(n_{0}\right)} \cdot C_{N, 2}^{\left(n_{1}\right)} \\
A X N=C_{N, 2}^{\left(n_{1}\right)} \cdot C_{1, N-1}^{\left(n_{0}\right)}-C_{1,2}^{\left(n_{0}\right)} \cdot C_{N, N-1}^{\left(n_{1}\right)}
\end{gathered}
$$

According to Equations (37) and (38), $W_{2}$ and $W_{N-1}$ are expressed in terms of $W_{3}, W_{4}, \ldots, W_{N-2}$, and can be easily substituted into the governing Equation (26). It should be noted that Equations (33) through (36) provides four boundary equations. In total, we have $N$ unknowns $W_{2}$, $W_{3}, \ldots, W_{N}$. In order to close the system, the discretized governing equation (26) has to be applied at $(N-4)$ mesh points. This can be done by applying Equation (26), at grid points $X_{3}, X_{4}, \ldots, X_{N-2}$. Substituting Equations (33), (35), (37) and (38) into Equation (26) gives the system of equations (39).

$$
\begin{aligned}
& S(X)\left(\sum_{j=3}^{N-2} D_{i j} \cdot W_{j}\right)+2 \cdot S^{(1)}\left(X_{i}\right) \cdot\left(\sum_{j=3}^{N-2} C_{i j} \cdot W_{j}\right)+S^{(2)}\left(X_{i}\right) \cdot\left(\sum_{j=3}^{N-2} B_{i j} \cdot W_{j}\right)+ \\
& P .\left(\sum_{j=3}^{N-2} B_{i j} \cdot W_{j}\right)+K_{1} \cdot W_{i}+K_{2} \cdot W_{i}^{3}-K_{3} \cdot\left(\sum_{j=3}^{N-2} B_{i j} \cdot W_{j}\right)-F=\Omega^{2} \cdot W_{i}(39)
\end{aligned}
$$

Assuming that the external dynamic distributed load changes as the deflection amplitude change, then the governing equations system (39) can be written as

$$
\begin{aligned}
& S(X)\left(\sum_{j=3}^{N-2} D_{i j} \cdot W_{j}\right)+2 \cdot S^{(1)}\left(X_{i}\right) \cdot\left(\sum_{j=3}^{N-2} C_{i j} \cdot W_{j}\right)+S^{(2)}\left(X_{i}\right) \cdot\left(\sum_{j=3}^{N-2} B_{i j} \cdot W_{j}\right)+ \\
& P .\left(\sum_{j=3}^{N-2} B_{i j} \cdot W_{j}\right)+K_{1} \cdot W_{i}+K_{2} \cdot W_{i}^{3}-K_{3} \cdot\left(\sum_{j=3}^{N-2} B_{i j} \cdot W_{j}\right)-F \cdot W_{i}=\Omega^{2} \cdot W_{i}
\end{aligned}
$$

It is noted that Equations (40) has $(\mathrm{N}-4)$ equations with $(\mathrm{N}-4)$ unknowns, which can be written in matrix eigen-value form as

$$
\begin{gathered}
{[A] .\{W\}+K_{2} \cdot\{W\}^{3}=\Omega^{2} \cdot\{W\}} \\
\{W\}=\left\{W_{3}, W_{4}, \ldots \ldots, W_{N-2}\right\}^{T}
\end{gathered}
$$

\section{Results}

In this section forced vibration of Euler-Bernoulli of nonuniform beams resting on two layer elastic foundations under axial and transverse load is analyzed. The GDQM is used to compute the first three natural frequencies and the corresponding mode shapes for the forced vibration of nonuniform under axial and transverse force with two cases of inertia ratio $S(X)=\left(1+\alpha_{1} X\right)^{\alpha_{2}}$, the first case: $1 \alpha_{1}=0.5, \alpha_{2}$ $=1.0$ and the second case: $\alpha_{1}=-1.0, \alpha_{2}=1.0$, with three different types of end conditions. Fifteen non-uniformly spaced grid points were chosen by the previous relation.

\subsection{Accuracy and Stability}

In order to discuss the stability and accuracy of the GDQM, uniform beams are solved using the present approach for implementing the boundary conditions and the results are compared with the exact results available in the literature. The exact solutions are introduced as found in Qiang [34] and Blevins [35] for uniform beam $S(X)=1.0$. The results are presented in Tables (1) through (3).

Tables (1) through (3) show the first three non-dimensional natural frequencies of uniform beam Clamped-Clamped Beam (C-C) Supported, Simply-Simply (S-S) Beam Supported and Clamped-Simply Beam (C-S) supported, respectively. Fifteen non-uniformly spaced grid points were chosen by the previous relation.

The absolute relative error typed in Tables (1) through (3) represents the accuracy of the GDQM. This absolute relative error can be defined by the formula, $\left|\frac{\text { Present-Exact }}{\text { Exact }} \times 100\right|$. Examining the three tables.

Table 1. The first three non-dimensional frequencies of uniform ClampedClamped beam.

\begin{tabular}{llll}
\hline Natural Frequency & $\mathbf{\Omega 1}$ & $\mathbf{\Omega 2}$ & $\mathbf{\Omega 3}$ \\
\hline Exact (Qiang [34], Blevins [35]) & 22.3733 & 61.6728 & 120.9034 \\
Present (SBCGM) & 22.3733 & 61.6728 & 120.9021 \\
Absolute relative error \% & 0.0000 & 0.0000 & 0.0011 \\
\hline
\end{tabular}

Table 2. The first three non-dimensional frequencies of uniform SimplySimply beam.

\begin{tabular}{llll}
\hline Natural Frequency & $\mathbf{\Omega 1}$ & $\mathbf{\Omega 2}$ & $\mathbf{\Omega 3}$ \\
\hline Exact (Qiang [34], Blevins [35]) & 9.8696 & 39.4784 & 88.8264 \\
Present (SBCGM) & 9.8696 & 39.4784 & 88.8249 \\
Absolute relative error \% & 0.0000 & 0.0000 & 0.0016 \\
\hline
\end{tabular}

Table 3. The first three non-dimensional frequencies of uniform ClampedSimply beam.

\begin{tabular}{llll}
\hline Natural Frequency & $\mathbf{\Omega 1}$ & $\mathbf{\Omega 2}$ & $\mathbf{\Omega 3}$ \\
\hline Exact (Qiang [34], Blevins [35]) & 15.4182 & 49.9648 & 104.2477 \\
Present (SBCGM) & 15.4182 & 49.9648 & 104.2471 \\
Absolute relative error \% & 0.0000 & 0.0000 & 0.0006 \\
\hline
\end{tabular}

\subsection{Results Using a Proposed Technique of GDQM}

Tables (4) and (5) show the first three non-dimensional natural frequencies of non-uniform beam resting on two layer elastic foundations with two cases of inertia ratio $S(X)=\left(1+\alpha_{1} X\right)^{\alpha_{2}}$, the first case: $1, \alpha_{1}=0.5, \alpha_{2}=1.0$ and the second case: $2, \alpha_{1}=-1.0, \alpha_{2}=1.0$, under the three sets of boundary conditions. Fifteen non-uniformly spaced grid points were chosen by the previous relation.

It can be observed from Table (4) and (5) that, the natural frequencies increase when the beam resting on two layer 
elastic foundations.

The corresponding mode shapes are presented in Figures (2-7). Figures (2-4) for the first case of inertia ratio and Figures (5-7) for the second case of inertia ratio.

Case (1):

Table 4. The first three non-dimensional frequencies of non-uniform supported beam $(P=1, F=1, S(X)=(1+0.5 X))$.

\begin{tabular}{llll}
\hline $\begin{array}{l}\text { Foundation } \\
\text { parameters }\end{array}$ & $\begin{array}{l}\text { Natural } \\
\text { Frequency (C-C) }\end{array}$ & $\begin{array}{l}\text { Natural } \\
\text { Frequency (S-S) }\end{array}$ & $\begin{array}{l}\text { Natural } \\
\text { Frequency (C-S) }\end{array}$ \\
\hline $\mathrm{K}_{1}=1.0$, & $\Omega 1=24.8883$ & $\Omega 1=11.0035$ & $\Omega 1=16.9279$ \\
$\mathrm{~K}_{2}=1.0$, & $\Omega 2=68.6339$ & $\Omega 2=43.9763$ & $\Omega 2=55.3994$ \\
$\mathrm{~K}_{3}=1.0$ & $\Omega 3=134.5731$ & $\Omega 3=98.9180$ & $\Omega 3=115.8263$ \\
\hline
\end{tabular}

Case (2):

Table 5. The first three non-dimensional frequencies of non-uniform supported beam $(P=1, F=1, S(X)=(1-X))$.

\begin{tabular}{llll}
\hline $\begin{array}{l}\text { Foundation } \\
\text { parameters }\end{array}$ & $\begin{array}{l}\text { Natural } \\
\text { Frequency (C-C) }\end{array}$ & $\begin{array}{l}\text { Natural } \\
\text { Frequency (S-S) }\end{array}$ & $\begin{array}{l}\text { Natural } \\
\text { Frequency (C-S) }\end{array}$ \\
\hline $\mathrm{K}_{1}=1.0$, & $\Omega 1=11.9742$ & $\Omega 1=6.3249$ & $\Omega 1=10.3991$ \\
$\mathrm{~K}_{2}=1.0$, & $\Omega 2=34.3839$ & $\Omega 2=24.6150$ & $\Omega 2=31.1571$ \\
$\mathrm{~K}_{3}=1.0$ & $\Omega 3=68.3635$ & $\Omega 3=53.5371$ & $\Omega 3=63.4720$ \\
\hline
\end{tabular}

Case (1):

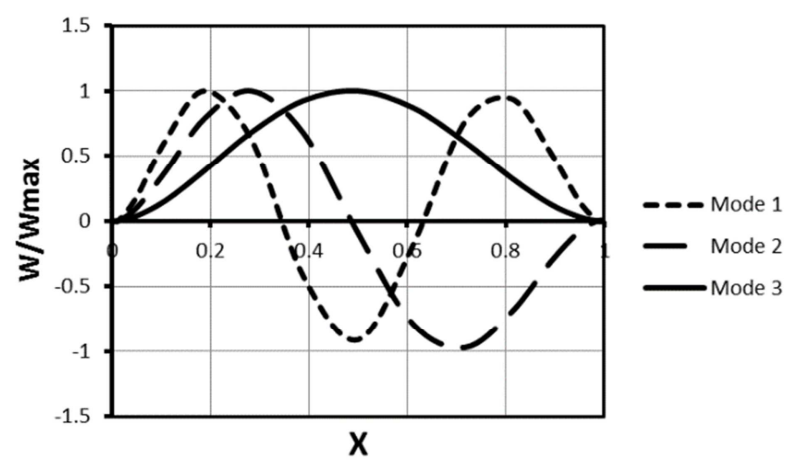

Figure 2. The first three mode shapes of non-uniform Clamped-Clamped supported beam $\left(K_{1}=1.0, \quad K_{2}=1.0, \quad K_{3}=1.0, P=1, \quad F=1\right.$, $S(X)=(1+0.5 X))$.

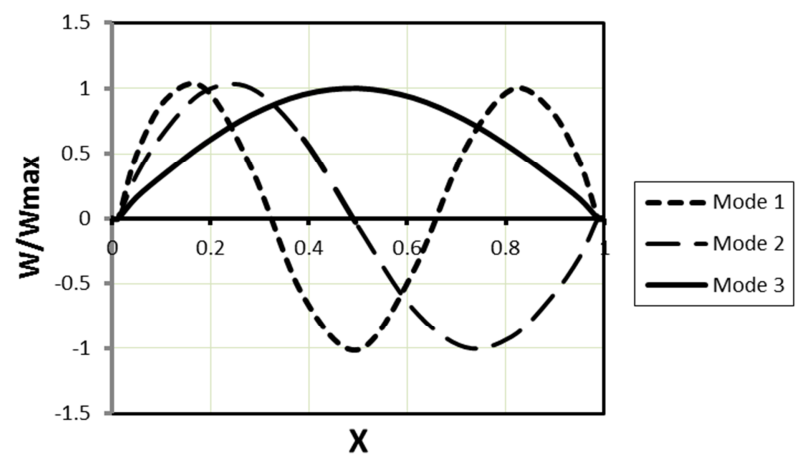

Figure 3. The first three mode shapes of non-uniform Simply-Simply supported beam $\left(K_{1}=1.0, K_{2}=1.0, K_{3}=1.0, P=1, F=1, S(X)=(1+0.5 X)\right)$.

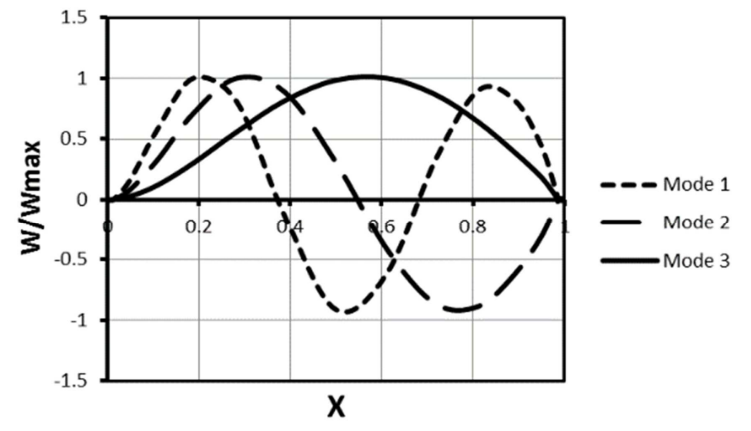

Figure 4. The first three mode shapes of non-uniform Clamped-Simply supported beam $\left(K_{1}=1.0, K_{2}=1.0, K_{3}=1.0, P=1, F=1, S(X)=(1+0.5 X)\right)$.

Case (2):

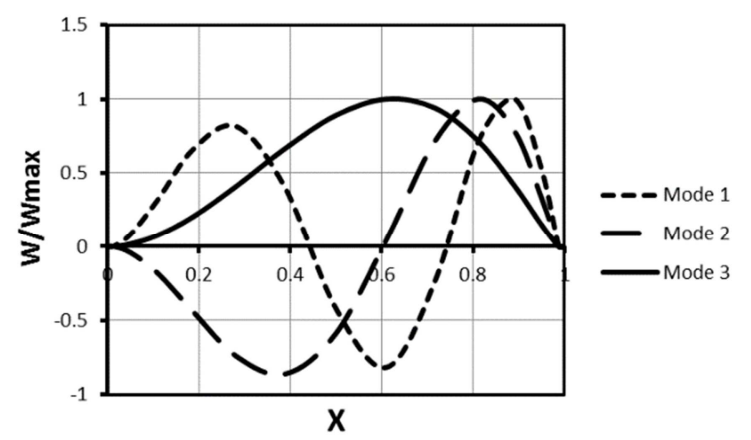

Figure 5. The first three mode shapes of non-uniform Clamped-Clamped supported beam $\left(K_{1}=1.0, K_{2}=1.0, K_{3}=1.0, P=1, F=1, S(X)=(1-X)\right)$.

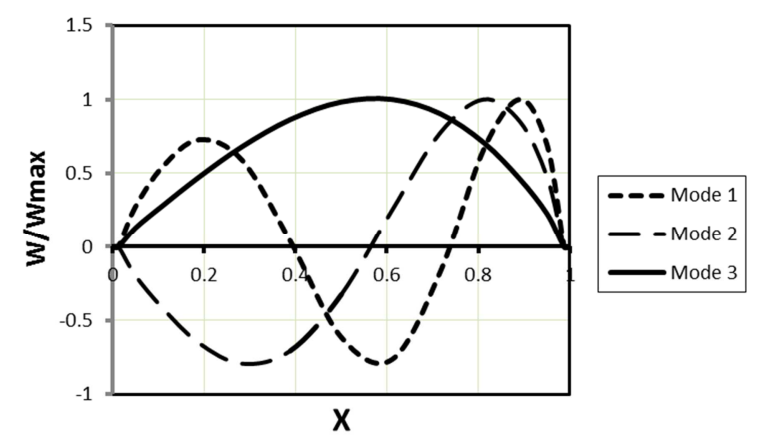

Figure 6. The first three mode shapes of non-uniform Simply - Simply supported beam $\left(K_{1}=1.0, K_{2}=1.0, K_{3}=1.0, P=1, F=1, S(X)=(1-X)\right)$.

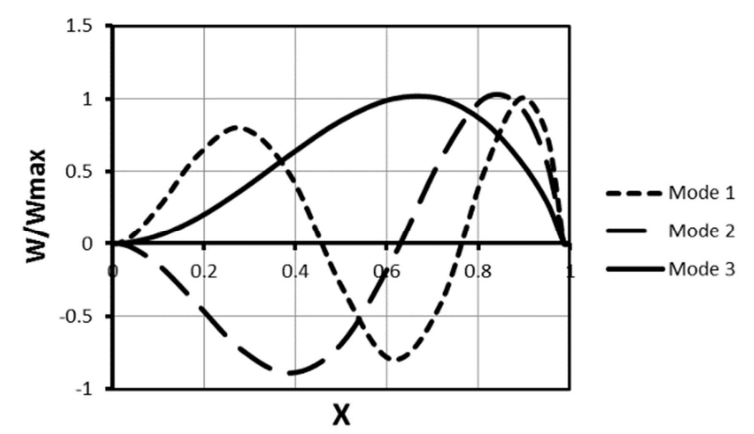

Figure 7. The first three mode shapes of non-uniform Clamped-Simply supported beam $\left(K_{1}=1.0, K_{2}=1.0, K_{3}=1.0, P=1, F=1, S(X)=(1-X)\right)$. 
To examine the effect of the non-linear elastic foundation " $\mathrm{K}_{2}$ ", we fix the other values of elastic foundations " $\mathrm{K}_{1}$ " and " $\mathrm{K}_{3}$ ", the value of axial load "P" and the value of distributed dynamic force "F". Then draw "K${ }_{2}$ " versus the natural frequency. It is clear that increasing the non-linear elastic foundation $" \mathrm{~K}_{2}$ " increases the natural frequency of the beam, Figures (8-10) for the first case of inertia ratio and Figures (11-13) for the second case of inertia ratio.

Case (1):

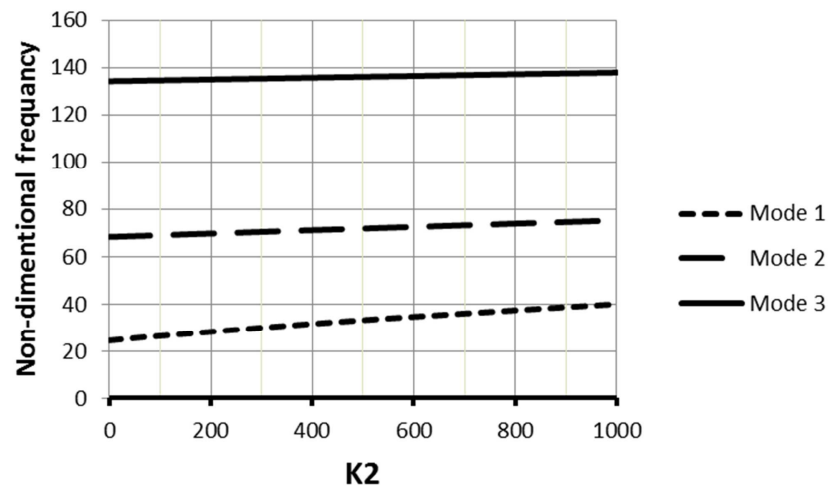

Figure 8. The first three non-dimensional frequencies of non-uniform Clamped-Clamped beam with various $K_{2} \quad(P=1.0, \quad F=1.0$, $S(X)=(1+0.5 X))$

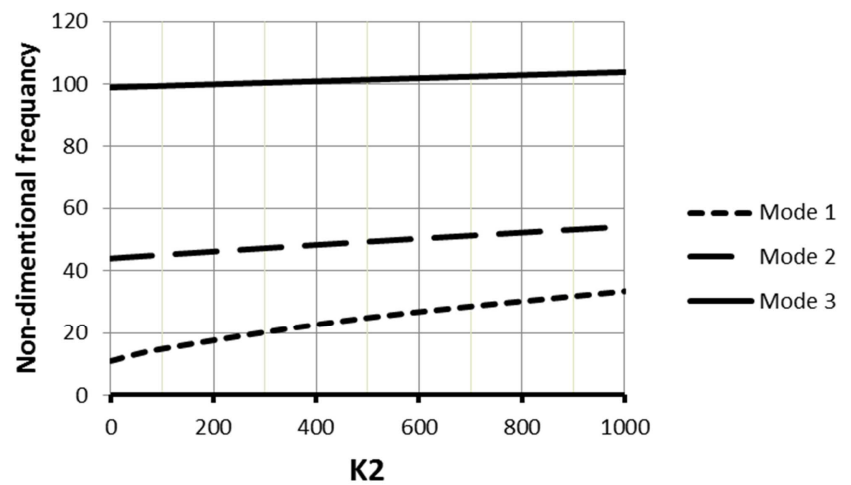

Figure 9. The first three non-dimensional frequencies of non-uniform Simply -Simply beam with various $K_{2}(P=1.0, F=1.0, S(X)=(1+0.5 X))$.

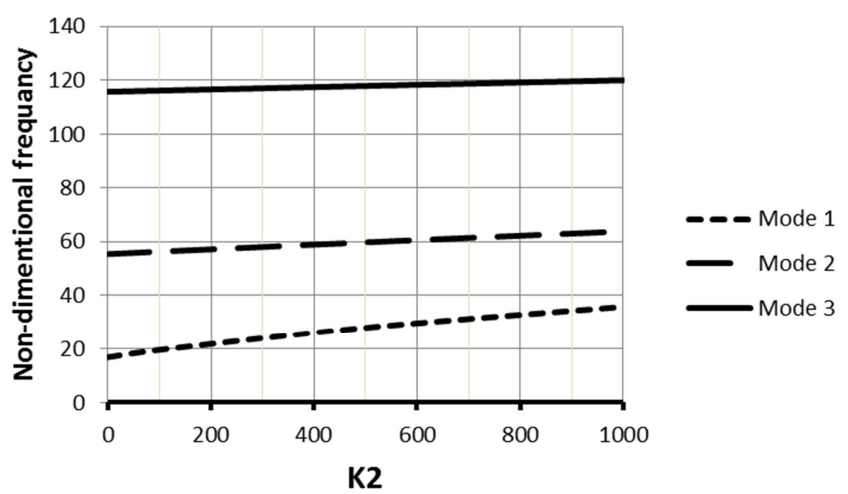

Figure 10. The first three non-dimensional frequencies of non-uniform Clamped-Simply beam with various $K_{2}(P=1.0, F=1.0, S(X)=(1+0.5 X))$.

Case (2):

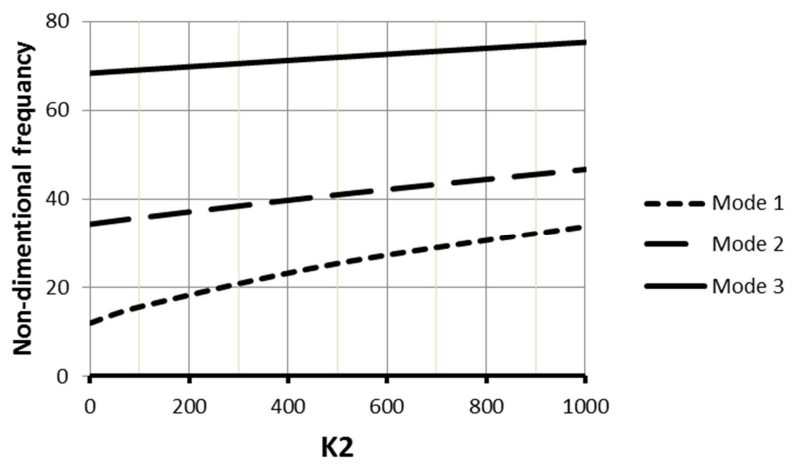

Figure 11. The first three non-dimensional frequencies of non-uniform Clamped-Clamped beam with various $K_{2}(P=1.0, F=1.0, S(X)=(1-X))$.

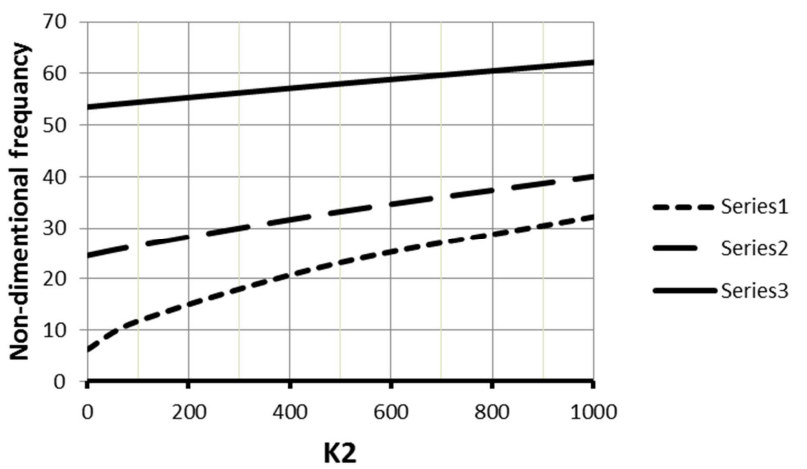

Figure 12. The first three non-dimensional frequencies of non-uniform Simply-Simply beam with various $K_{2}(P=1.0, F=1.0, S(X)=(1-X))$.

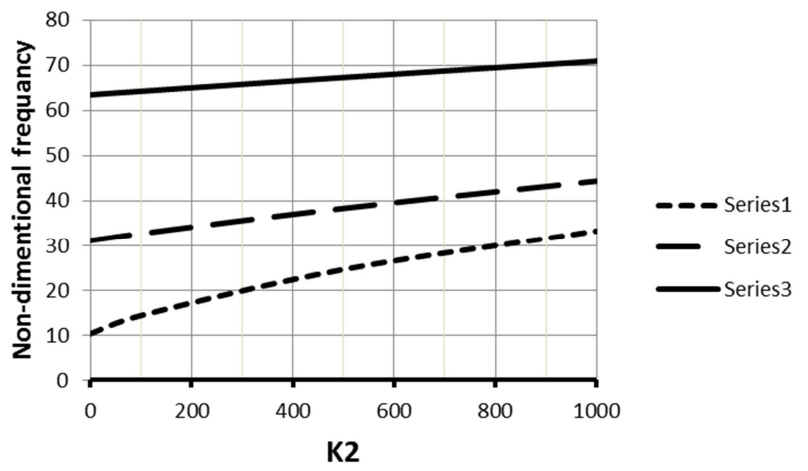

Figure 13. The first three non-dimensional frequencies of non-uniform Clamped-Simply beam with various $K_{2}(P=1.0, F=1.0, S(X)=(1-X))$.

\section{Conclusion}

In this paper, an efficient algorithm based on a new combination of a GDQM and Newton's method presented for solving eigenvalue problems of non-uniform beams resting on two layer elastic foundations. Appropriate boundary conditions and the GDQM are applied to transform the partial differential equations of non-uniform beams resting on two layer elastic foundations into discrete eigenvalue problems. The results for various types of boundary conditions were compared with the results obtained by exact solution in case of uniform beam supported on elastic support.

From the parametric study of nonlinear elastic foundation of vibration analysis for various types of boundary conditions, that, 
the natural frequency of the beam increases with increasing the nonlinear Winkler (normal) foundation parameter $\left(\mathrm{K}_{2}\right)$

\section{References}

[1] Lai Y. C., Ting B. Y., Lee W. S., Becker WR. Dynamic response of beams on elastic foundation. J. Struct. Eng. ASCE 1992; 118: 853-58.

[2] Thambiratnam D., Zhuge Y., Free vibration analysis of beams on elastic foundations. Comput Struct 1996; 60 (6): 971-80.

[3] Ayvaz Y., Ozgan K., Application of modified Vlasov model to free vibration analysis of beams resting on elastic foundations. J Sound Vib 2002; 255 (1): 111-27.

[4] Irie T., Yamada G., Takahashi I., Vibration and stability of a nonuniform Timoshenko beam subjected to a flower force. Sound Vib 1980; 70: 503-12.

[5] Gutierrez R. H., Laura P. A. A., Rossi R. E., Fundamental frequency of vibration of a Timoshenko beam of nonuniform thickness. J Sound Vib 1991; 145: 241-5.

[6] Chen C. N., Vibration of prismatic beam on an elastic foundation by the differential quadrature element method. Comput Struct 2000; 77: 1-9.

[7] Chen C. N., DQEM Vibration analysis of non-prismatic shear deformable beams resting on elastic foundations. J Sound Vib 2002; 255 (5): 989-99.

[8] Malekzadeh P., Karami G., Farid M., DQEM for free vibration analysis of Timoshenko beams on elastic foundations. Comput Mech 2003; 31: 219-28.

[9] Karami G., Malekzadeh P., Shahpari S. A. A., DQEM for free vibration of shear deformable nonuniform beams with general boundary conditions. Eng Struct 2003; 25: 1169-78.

[10] Chen WQ, Lu C. F., Bain Z. G., A mixed method for bending and free vibration of beams resting on Pasternak elastic foundations. Appl Math Model 2004; 28: 877-90.

[11] Pellicano F., Mastroddi F., Nonlinear dynamics of a beam on elastic foundation. Nonlinear Dyn 1988; 14: 335-55.

[12] Qaisi M. I., Nonlinear normal modes of a continuous system. J Sound Vib 1998; 209 (4): 561-69.

[13] Nayfeh A. H., Nayfeh S. A., On nonlinear modes of continuous systems. Vib Acous ASME 1994; 116: 129-36.

[14] Maccari A., The asymptotic perturbation method for nonlinear continuous systems. Nonlinear Dyn 1999; 19: 1-18.

[15] Coskun I., Engin H., Nonlinear vibrations of a beam on an elastic foundation. J Sound Vib 1999; 223 (3): 335-54.

[16] Balkaya M., Kaya M. O., and Sağlamer A., Analysis of the vibration of an elastic beam supported on elastic soil using the differential transform method, Archive of Applied Mechanics, 2009; 79 (2):135-146.

[17] B. Ozturk, S. B. Coskun, The Homotopy Perturbation Method for free vibration analysis of beam on elastic foundation, Structural Engineering and Mechanics, 2011; 37 (4): 415-425.

[18] Avramidis I. E., Morfidis K., Bending of beams on threeparameter elastic foundation, International Journal of Solids and Structures, 2006; 43: 357-375.

[19] Abrate, S., Vibrations of Non-Uniform Rods and Beams, Journal of Sound and Vibration, 1995; 185: 703-716.

[20] Gottlieb, H. P. W., Comments on Vibrations of Non- Uniform Beams and Rods, Journal of Sound and Vibration, 1996; 195: 139-141.

[21] Naguleswaran, S., Comments on Vibration of Non- Uniform Beams and Rods, Journal of Sound and Vibration, 1996; 195: 331-337.

[22] Hodges, D. H., Chung, Y. Y. and Shang, X. Y., Discrete Transfer Matrix Method for Non-Uniform Rotating Beams, Journal of Sound and Vibration, 1994; 169: 276-283.

[23] Sharma, S. P. and DasGupta, S., Bending Problem of Axially Constrained Beams on Nonlinear Elastic Foundations, International Journal of Solid and Structures, 1975; 11: 853-859.

[24] Beaufait, F. W. and Hoadley, P. W., Analysis of Elastic Beams on Nonlinear Foundation," Computers \& Structures, 1980; 12: 669-676.

[25] Kuo, Y. H. and Lee, S. Y., "Deflection of Nonuniform Beams Resting on a Nonlinear Elastic Foundation," Computers \& Structures, 1994; 51: 513-519.

[26] Chen, C. N., Solution of Beam on Elastic Foundation by DEQM, Journal of Engineering Mechanics, 1998; 124: 1381-1384.

[27] Bagheri S., Nikkar A., Ghaffarzadeh H., Study of nonlinear vibration of Euler-Bernoulli beams by using analytical approximate techniques. Latin American Journal of Solids and Structures, 2014; 11: 157-168.

[28] Nikkar A., Bagheri S., Saravi M., Study of nonlinear vibration of Euler-Bernoulli beams by using analytical approximate techniques. Latin American Journal of Solids and Structures, 2014; 11: 320-329.

[29] Li, L., Zhang, D., Dynamic analysis of rotating axially FG tapered beams based on a new rigid-flexible coupled dynamic model using the B-spline method. Composite Structures, 2015; 124: 357-367.

[30] Ramzy M. Abumandour, Islam M. Eldesoky, Mohamed A. Safan, Rizk-Allah R. M. and Fathi A. Abdelmgeed, Deflection of NonUniform Beams Resting on a Non-linear Elastic Foundation using (GDQM), International Conference on Materials and Structural Integrity (ICMSI2016), Paris, France, June 2-4, 2016.

[31] Ramzy M. Abumandour, Kamel M. H. and Bichir S., Application of the GDQ Method to Structural Analysis, International Journal of Mathematics and Computational Science, 2016; 2 (1): 8-19.

[32] Ramzy M. Abumandour, Kamel M. H. and Nassar M. M., Application of the GDQ method to vibration analysis, International Journal of Mathematics and Computational Science, 2015; 1 (5): 242-249.

[33] Chang. S., Differential Quadrature and its application in engineering," Springer, (2000).

[34] Qiang Guo and Zhong, H., Non-linear Vibration Analysis of Beams by a Spline-based differential quadrature. Journal of Sound and Vibration, 2004; 269: 405-432.

[35] Blevins, R. D., Formulas for Natural Frequency and Mode Shapes. Malabur, Florida. Robert E. Krieger, 1984. 